\title{
Robust Design of Dual-Input Power System Stabilizer Using Chaotic JAYA Algorithm
}

\author{
Badr M. Alshammari ${ }^{1} \mathbb{D}$, Anouar Farah ${ }^{1,2, *}$, Khalid Alqunun ${ }^{1}$ and Tawfik Guesmi ${ }^{1,2}$ \\ 1 Department of Electrical Engineering, University of Ha'il, Ha'il 2240, Saudi Arabia; \\ bms.alshammari@uoh.edu.sa (B.M.A.); kh.alqunun@uoh.edu.sa (K.A.); tawfik.guesmi@istmt.rnu.tn (T.G.) \\ 2 National Engineering School of Sfax, University of Sfax, Sfax 3038, Tunisia \\ * Correspondence: farah.anouar@gmail.com
}

check for updates

Citation: Alshammari, B.M.; Farah, A.; Alqunun, K.; Guesmi, T. Robust Design of Dual-Input Power System Stabilizer Using Chaotic JAYA

Algorithm. Energies 2021, 14, 5294. https://doi.org/10.3390/en14175294

Academic Editors: Nicu Bizon, Mihai Oproescu, Philippe Poure, Rocío Pérez de Prado and Abdessattar Abdelkefi

Received: 14 May 2021

Accepted: 3 August 2021

Published: 26 August 2021

Publisher's Note: MDPI stays neutral with regard to jurisdictional claims in published maps and institutional affiliations.

Copyright: (c) 2021 by the authors. Licensee MDPI, Basel, Switzerland. This article is an open access article distributed under the terms and conditions of the Creative Commons Attribution (CC BY) license (https:// creativecommons.org/licenses/by/ $4.0 /)$.

\begin{abstract}
This work aims to improve the stability of a system that consists of one generator using a dual-input stabilizer of a power system. For this purpose, a new design method based on a chaotic JAYA algorithm is proposed. This algorithm hybridizes the original JAYA algorithm with chaos to improve its exploration and exploitation capabilities. Indeed, the disordered numbers generated by the chaotic map are exploited to control the standard JAYA algorithm's search equations. The issue of design is stated as an optimization problem. The proposed technique is involved in the selection of optimal values of the dual-input power system stabilizer (PSS) parameters. The efficiency of the proposed controller is assessed under various loading conditions and compared with the original JAYA, cuckoo search and particle swarm optimization (PSO) algorithms. The target function consists of the integration of absolute error multiplied by the time, including the speed deviation is considered for the controller design method. The controller tuned by a chaotic JAYA algorithm is tested using a single machine infinite bus (SMIB) power system. The findings of the simulation results demonstrate the robustness and effectiveness of the suggested method in damping oscillations over an extended range of loading conditions.
\end{abstract}

Keywords: dual-input PSS; chaotic map; power system stabilizer; JAYA algorithm; ITAE

\section{Introduction}

Power system stability becomes an important issue for the researchers in power system protection. A steady increase in electric power demand leads to a power system's extension and the maximum power transfer in the lines. As a consequence, the operation of the power system is closer to the small-signal stability limits. Keeping the above points in consideration, the power transfer in heavy loads state favors the emergence of low-frequency oscillations $(0.1-0.8 \mathrm{~Hz})$. In some cases, this oscillatory instability may cause significant damage, such as system blackouts or the generator tripping from the power system.

The integration of an automatic voltage regulator (AVR) characterized by a high gain and rapid response in a modern power system induces low-frequency electromechanical oscillations. Also, the power transfer using weak transmission lines, small disturbances such as transmission lines' parameter variation, sudden small changes in loads, etc., lead to low-frequency oscillations, ranging between $0.2-0.3 \mathrm{~Hz}$ [1]. The widely used solution to address low-frequency oscillations is implementing a power system stabilizer (PSS) controller. The primary function of PSS is to increase the synchronous machine damping by adding a stabilizing signal to the AVR [2]. The excitation system's modulation allows the generation of damping torque in phase with rotor speed variation in the turbine shaft. In power system operation, PSS must produce good effectiveness in damping the electromechanical oscillations. The conventional PSS parameters' selection problem is solved using a power system model that is linearized. The damping of electromechanical oscillations, especially the inter-area modes, is highly affected by the change of loading 
conditions and the power system's topology. In these conditions, PSS is not able to provide satisfactory damping characteristics. Several works have focused on robust PSS via new design techniques or other PSS structures [3].

The first technique to achieve good robustness of PSS is by implementing new strategies to guarantee sufficient damping of electromechanical oscillations. These methods include classical control and meta-heuristic optimization techniques. Classical control approaches involve optimal adaptive and intelligent control. Metaheuristic algorithms such as PSO, genetic algorithm (GA) and teaching-learning-based optimization (TLBO) are also applied for selecting optimal PSS parameters. In the second approach, the researchers proposed several new PSS structures to improve power system stability like multi-input PSS [4], fuzzy logic-based PID PSS [5], multi-band PSS [3], proportional, integral, and derivative (PID)-based PSS [6], etc.

Recently, many engineering optimization problems have been addressed using metaheuristic algorithms due to their effectiveness [7-9]. Despite the differences between the meta-heuristic algorithms, their evolution process is based on exploration and exploitation phases (also called diversification and intensification). During the exploration phase, a given meta-heuristic algorithm investigates the search space to look for optimal solutions. By contrast, the exploitation step is in relation to a local search among the obtained solution to improve it. The main challenging task is to ensure a good balance between the two phases mentioned above [10].

JAYA is an optimization algorithm introduced by R.V. Rao for solving different types of engineering problems [11,12]. This technique has gained the attention of several researchers due to its simplicity and robustness. Besides, there are no specific parameters to be adjusted in the optimization process, only the common ones (i.e., the number of generations, population size and termination criterion) are required. Several works demonstrated that the JAYA algorithm outperforms other optimization algorithms in terms of solution quality. The main idea behind this technique is to push the results obtained thus far toward the best solution by avoiding the worst ones. Yet, this algorithm deficiency lies in premature convergence, therefore, it can fall in local optima $[13,14]$.

Chaos as a technique has been demonstrated as a powerful approach for improving optimization algorithms' performance [15-17]. It is defined as the study of nonlinear dynamical systems. The main merits of chaos are the sensitivity to initial circumstances and quasi-stochastic and ergodicity characteristics. The integration of chaotic values into optimization algorithms allows them to explore the search space. The acquired high-level diversification of the candidate solutions helps the obtained optimization algorithms to escape from local optima. Several studies used chaos theory in optimization, such as the chaotic crow search algorithm [18], chaotic whale optimizer [19], chaotic salp swarm algorithm [20], chaotic atom search optimization [21], chaotic antlion algorithm [22] and chaotic teaching-learning algorithm [23]. The integration of chaos in optimization algorithms can be summarized in three groups: chaotic local search, replacement of random numbers by chaotic sequence and the adjustment of optimization algorithms' control parameters.

The meta-heuristic algorithm has gained the attention of several researchers for finding the solution to power system problems. In [3], the authors use a new design method based on PSO, the culture algorithm and co-evolutionary techniques for tuning the parameters of a multi-band PSS (MB-PSS). Wesley et al. [24] proposed memetic algorithms by hybridizing the PSO, bat algorithm and gravitational search algorithm (GSO) for a robust selection of power system stabilizer. In this work, conventional PSS and multi-band PSS4B structures are used. A traditional lead-lag PSS structure is involved in [25] to improve the power system stability by using improved whale optimization. The structure of the classical PSS includes only one input, which is the speed or active power deviations. Some works revealed that a power system's damping capability could be improved by applying additional input signals to PSS. In [26], a comparative study is conducted for three IEEEPSSs. The simulation results confirm the superiority of dual-input PSS compared to single-input PSS. The signals inputs of the employed PSS are the speed deviation and 
electric torque or power. The authors proposed a chaotic ant swarm optimization (CASO) to design single- and dual-input PSSs [4].

In the present paper, we present a hybrid technique called the chaotic JAYA algorithm (C-JAYA) by embedding the chaos in the original JAYA algorithm. In our approach, the C-Jaya algorithm's performance, conceived to look for the optimal solution, is improved by implementing three mutually exclusive search equations. The proposed C-JAYA is exploited to find a dual-input PSS's optimal parameters and evaluated against a PSS controller tuned by the JAYA algorithm (JAYAPSS), PSOPSS and CSPSS. The simulation results confirmed that the proposed design method could provide a good damping performance.

The essential contributions of this work can be listed as follows:

- $\quad$ To investigate the performance of C-JAYA in designing PSS.

- To demonstrate the robustness of a dual-input PSS structure.

- To study the potential benefit of C-JAYA compared to the original JAYA, PSO and cuckoo search techniques.

- To show the efficacy of the suggested C-JAYAPSS controller over an extended range of loading conditions.

The remaining sections of this work are briefly introduced as follows. In Section 2, we will present the mathematical model of the system. Section 3 will deal with the standard JAYA algorithm. The chaotic JAYA algorithm (C-JAYA) is discussed in Section 4. Section 5 details the design approach. Section will gather all simulations' results with different loading conditions. Section 7 is dedicated to the conclusion.

\section{Mathematical Model}

In this part, we will deal with the mathematical model of both the power system and controller.

\subsection{Generator}

We will use in our study a SMIB as a test system, as shown in Figure 1. The classical third-order model describes the synchronous machine as follows [26]:

$$
\begin{gathered}
\dot{\delta}=\omega_{b}\left(\omega_{i}-1\right) \\
\dot{\omega}_{i}=\frac{1}{M_{i}}\left(P_{m i}-P_{e i}-D_{i}\left(\omega_{i}-1\right)\right) \\
\dot{E}_{q i}^{\prime}=\frac{1}{T_{d o}^{\prime}}\left(E_{f d i}-\left(x_{d i}-x_{d i}^{\prime}\right) i_{d i}-E_{q i}^{\prime}\right)
\end{gathered}
$$

where parameters like:

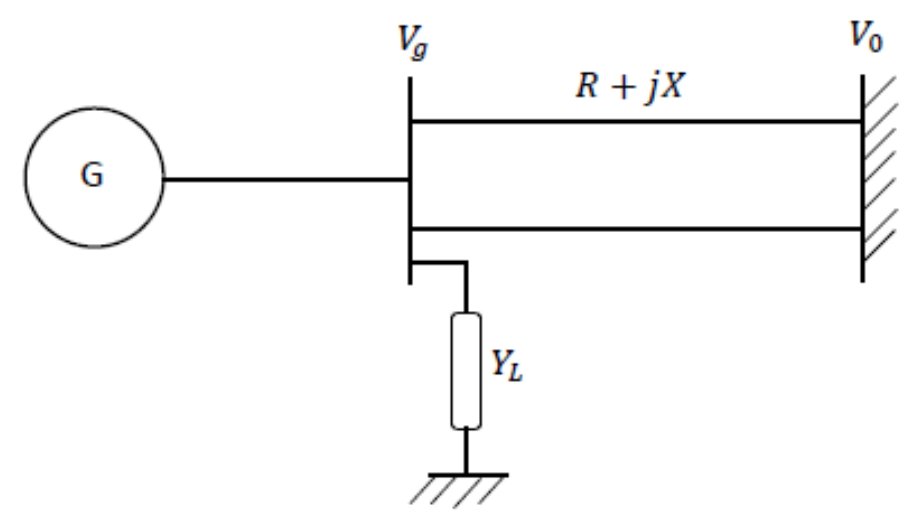

Figure 1. SMIB test system.

The rotor angle and angular speed are $\delta_{i}$ and $\omega_{i}$, respectively. The damping coefficient and inertia constant rae $D_{i}$ and $M_{i}$, respectively. The field open circuit transient time 
constant is $T_{d 0}^{\prime}$. The base frequency value is $\omega_{b}$ expressed in $\mathrm{rad} / \mathrm{s} . x_{d}^{\prime}$ and $x_{d}$ represent the $\mathrm{d}$-axis reactance and the transient one of the synchronous machine, respectively. $i_{d i}$ and $i_{q i}$ express the $d$-axis and $q$-axis armature current. $E_{f d i}$ and $E_{q i}^{\prime}$ reresent the field voltage and the internal one, respectively. Finally, the electrical power is expressed in the following equation:

$$
P_{e}=E_{q i}^{\prime} i_{q i}-\left(x_{q i}-x_{d i}^{\prime}\right) i_{d i} i_{q i}
$$

\subsection{Excitation System and Stabilize Models}

Figure 2 depicts the system exciter named IEEE Type-ST1. Its model is represented by the following mathematical equation:

$$
\dot{E}_{f d i}=\frac{1}{T_{A i}}\left(-E_{f d i}+K_{A}\left(V_{r e f}-V_{g}+V_{p s s}\right)\right)
$$

where $K_{A}$ and $T_{A}$ are the gain and time constant of the AVR, the reference voltage is $V_{\text {ref }}$, the terminal voltage is $V_{g}$ and the supplementary signal from the PSS is $V_{p s s}$.

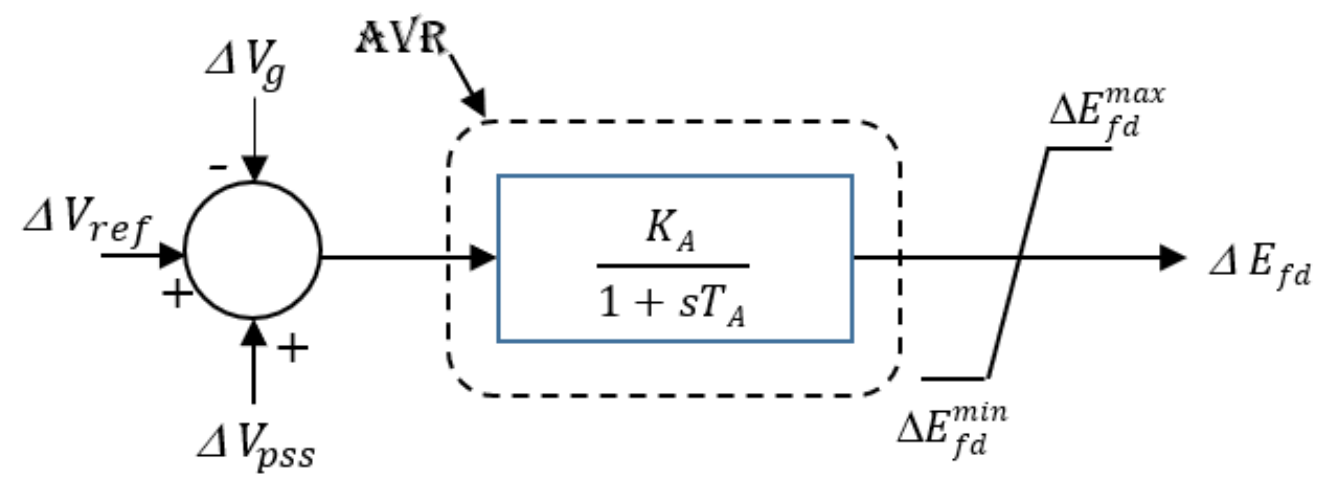

Figure 2. IEEE type-ST1 exciter.

Where

$$
\begin{gathered}
V_{g}=\sqrt{V_{g d}^{2}+V_{g q}^{2}} \\
V_{g d}=x_{q} i_{q} \\
V_{g q}=E_{q-}^{\prime} x_{d}^{\prime} i_{d}
\end{gathered}
$$

The PSS is added in to provide a damping torque component in the exciter. Figure 3 represent the block diagram of the dual-input PSS (DIPSS) named PSS3B. Two inputs are used in this PSS, which are the torque and speed deviations.

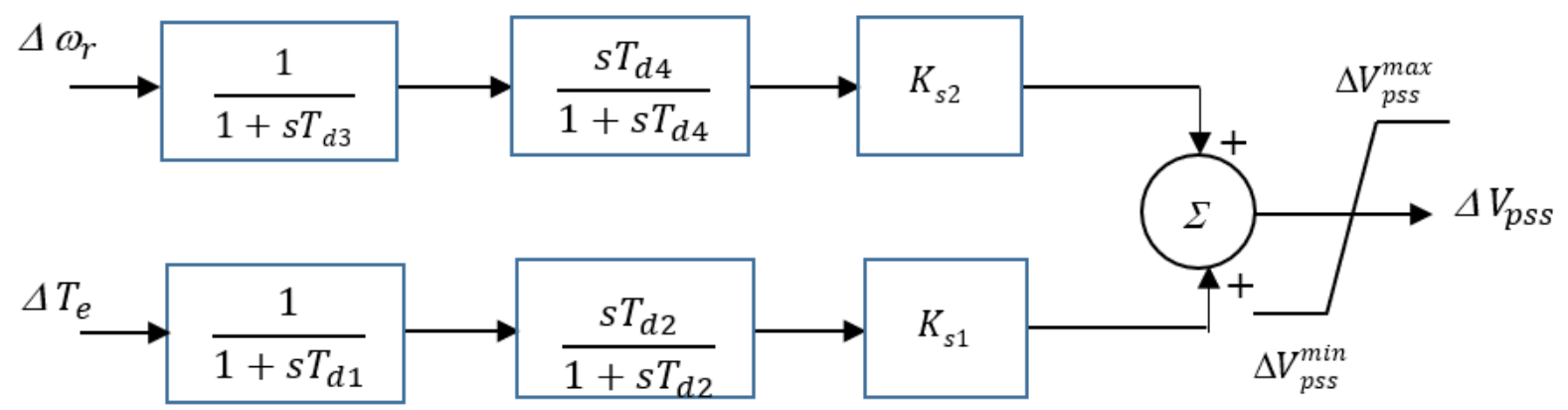

Figure 3. DIPSS block diagram. 


\section{Classical JAYA}

To solve optimization problems, R.V. Rao suggested the JAYA algorithm [27]. The main concern of JAYA is to get the optimal solution by avoiding the worst ones and tending to reach the best. JAYA differs from other optimization techniques in the respect that it is free of control parameters, which means only two common parameters are required, i.e., the number of generations and population size [11].

$\mathrm{g}(\mathrm{x})$ is the objective function and $\mathrm{d}$ represents the number of design variables. The following candidate solution is: $x_{i}=\left(x_{i, 1}, x_{i, 2}, x_{i, 3}, \ldots \ldots x_{i, d}\right)$. The best value of $\mathrm{g}(x)$ is obtained for $x_{\text {best }}=\left(x_{\text {best }, 1}, x_{\text {best }, 2}, x_{\text {best }, 3}, \ldots \ldots x_{\text {best }, d}\right)$, whereas the worst candidate is $x_{\text {worst }}=\left(x_{\text {worst }, 1}, x_{\text {worst }, 2}, x_{\text {worst }, 3}, \ldots \ldots . x_{\text {worst }, d}\right)$. The updated solution is given as follows:

$$
X_{n e w, j}=X_{i, j}+\operatorname{rand}_{1}\left(X_{\text {best } j}-\left\lfloor X_{i, j}\right\rfloor\right)-\operatorname{rand}_{2}\left(X_{\text {worst } j}-\left\lfloor X_{i, j}\right\rfloor\right)
$$

where the worst and best candidates are $X_{\text {worst } j}$ and $X_{\text {best }}$, respectively. $X_{\text {new } i, j}$ is the updated solution of $X_{i, j}$ and $\left\lfloor X_{i, j}\right\rfloor$ is its absolute value. Besides, the previous equation include two, random numbers $\operatorname{rand}_{1}$ and $\operatorname{rand}_{2}$. $\operatorname{rand}_{1}\left(X_{\text {best } j}-\left\lfloor X_{i, j}\right\rfloor\right)$ expresses the tendency toward the best solution, whereas the term $\operatorname{rand}_{2}\left(X_{\text {worst } j}-\left\lfloor X_{i, j}\right\rfloor\right)$ represents the avoidance of the worst solution. At this level, we will only accept $x_{n e w, i}$ if it gives better values of the objective function.

The JAYA flowchart is shown in Figure 4.

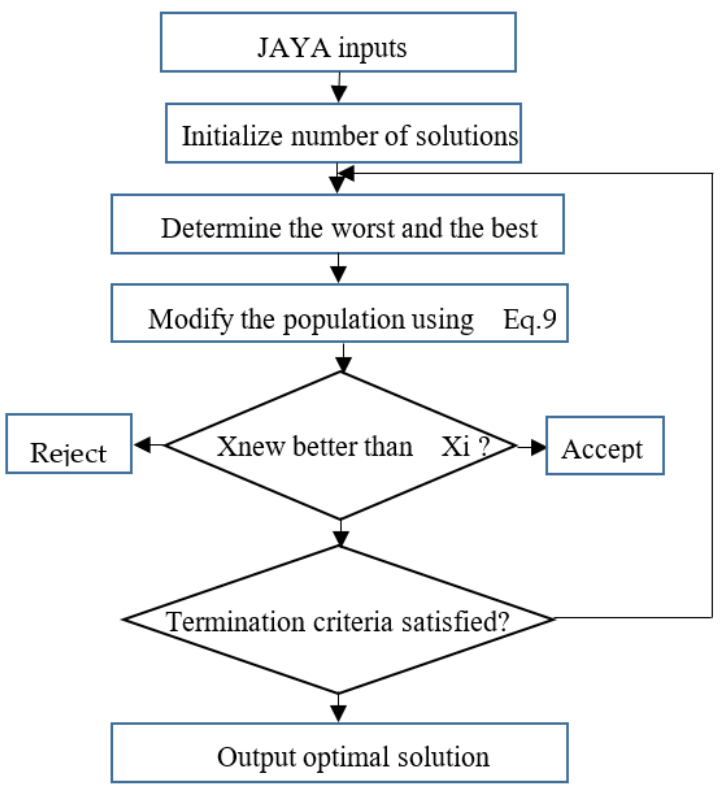

Figure 4. Flowchart of the original JAYA algorithm.

\section{Proposed Chaotic JAYA}

\subsection{Chaotic Map}

The purpose of using chaos in an optimization algorithm is to exploit its easy implementation, good dynamic behavior and exceptional ability to increase population diversity. Several works embedded the chaos in an evolutionary algorithm [15-23]. We have incorporated chaos in the JAYA technique in our work to improve its searching behavior and avoid falling in local optima.

We will use the logistic map [28] characterized by a high sensitivity to even a tiny change of the initial condition, random-like and ergodic. The logistic map is of onedimensional chaotic systems defined by the following equation:

$$
\beta^{k+1}=\mu \beta^{k}\left(1-\beta^{k}\right), k=1,2, \ldots \beta \in[0,1]
$$


where $\mu$ is the system parameter $(\mu \in[0,4])$. The chaotic map is defined in interval $[0,1]$. The bifurcation diagram for the logistic map is shown in Figure 5. The bifurcation diagram of the logistic map is the fruit of plotting, as a function of $\mu$, a series of values for $\beta$, achieved by starting with a random value, iterating it many times and eliminating the first points corresponding to values before the iterates converge to the attractor.

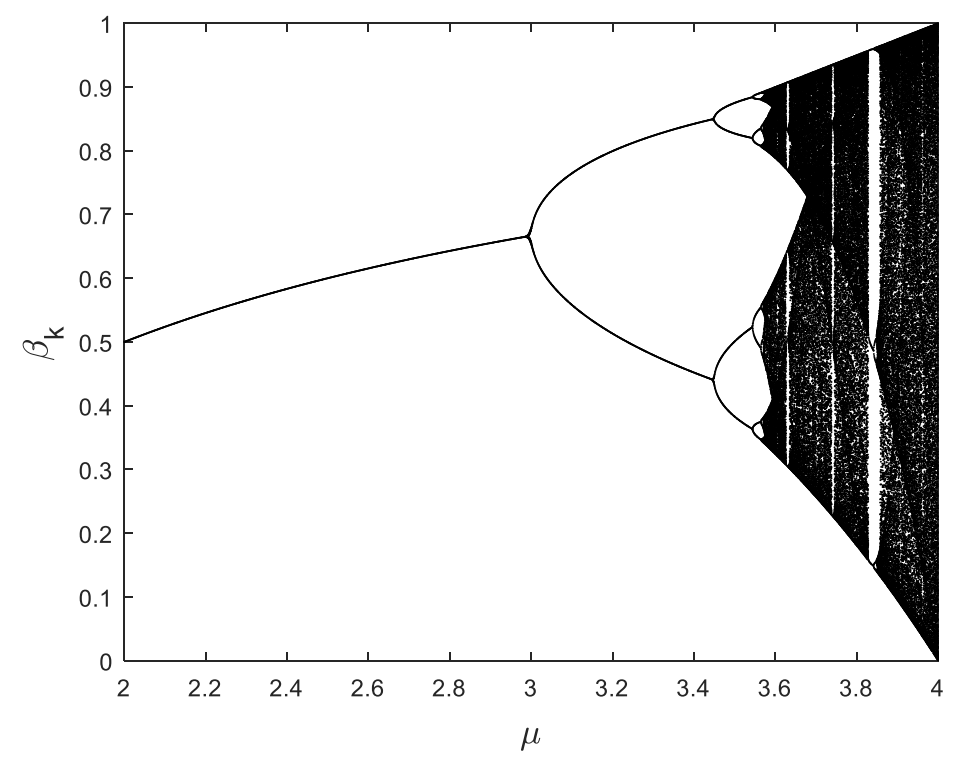

Figure 5. The bifurcation diagram of the logistic map.

The chaotic maps are embedded in an optimization algorithm thanks to their pseudorandom behavior. The sensitivity of the initial conditions and control parameters allows good results in the generation of chaotic sequences. In this paper, the logistic map is used to substitute the random numbers in the original JAYA algorithm.

\subsection{Chaotic JAYA Algorithm}

The original JAYA algorithm suffers from some deficiencies such as premature convergence and lack of population diversity. As a consequence, it can fall in local optima. The effectiveness of a given method is mainly related to achieving a compromise between exploitation and exploration abilities. The exploitation is linked to the convergence toward the optimal solutions in a speedy manner. In contrast, exploration is recognized as the inspection of the promising region in the search space.

In [10], the authors suggested a new JAYA by integrating the chaos in the standard JAYA. To reach a compromise between exploitation and exploration, three mutually exclusive search equations are proposed as follows [10]:

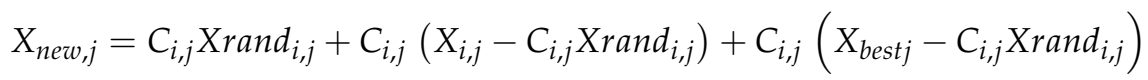

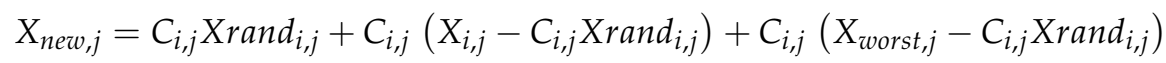

$$
\begin{aligned}
& X_{n e w, j}=C_{i, j} \text { Xbest }_{j}+C_{i, j}\left(\text { Xrand }_{i, j}-S_{F} \text { Xbest }_{j}\right)
\end{aligned}
$$

where $C_{i, j}$ is the value of a chaotic number produced by the logistic map.

The parameter $S_{F}$ can chaotically take two numbers ( 1 or 2$)$ and can be defined as follows: $S_{F}=\operatorname{round}\left[1+C_{i, j}\right]$.

The local search ability of the chaotic JAYA is improved by involving Equation (13). Unfortunately, due to having a huge number of local optima, premature convergence is generally encountered. Therefore, the global optimum cannot be reached. This problem can be addressed when the scaling factor takes its maximum value. In this case, trapping 
in local optima is avoided, and the overall search behavior of the standard algorithm is enhanced.

It can be inferred from the first mutation (Equation (11)) that the diversity of the elements of the population is improved. The second mutation (Equation (12)) enhances the overall solution by escaping the worst alternatives. It worth noting that the selection process among the above equations is carried out randomly. Figure 6 presents a C-JAYA flowchart.

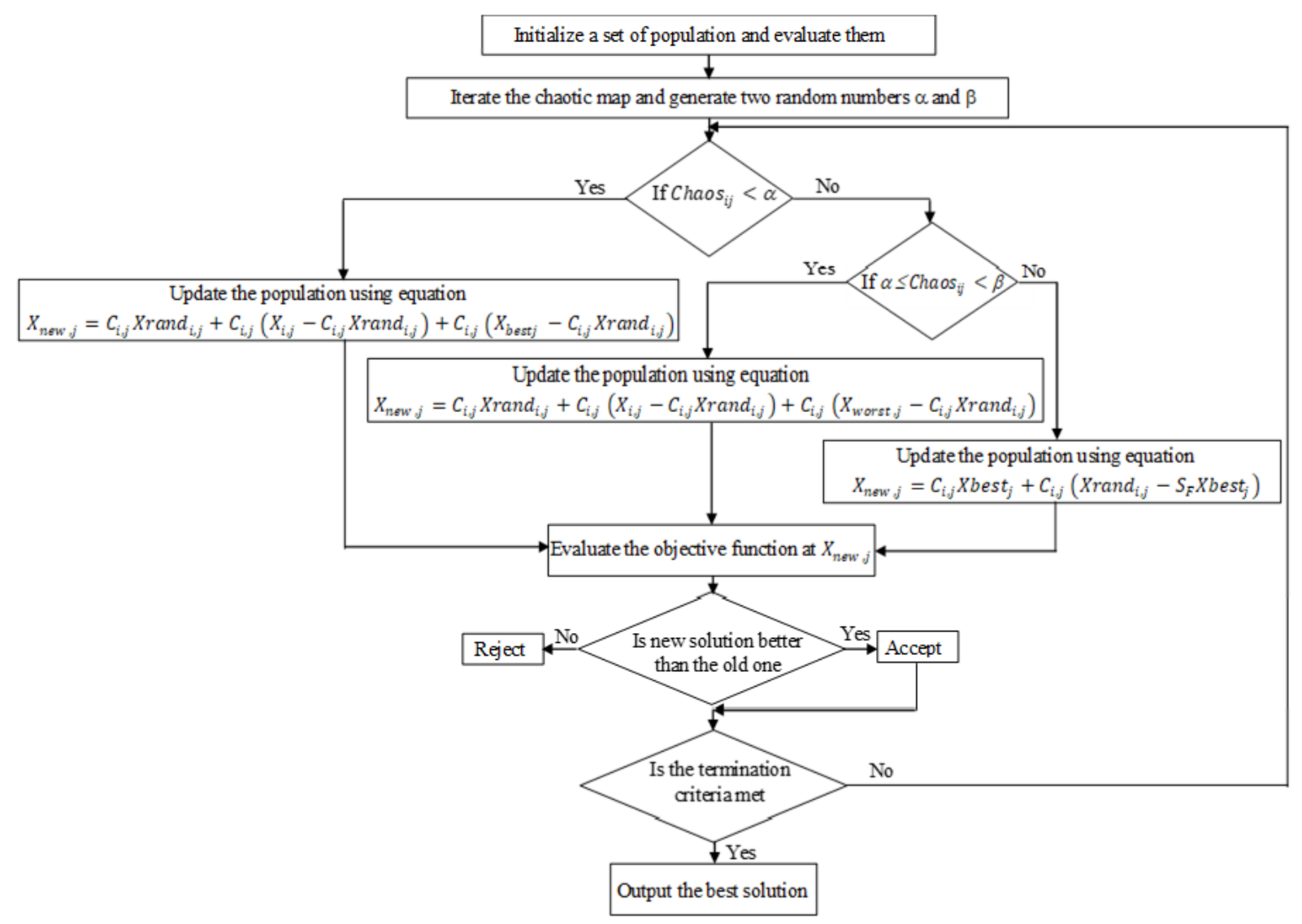

Figure 6. C-JAYA flowchart.

\section{Design Approach}

The C-JAYA algorithm is involved in designing the suggested dual-input PSS parameters. The proposed controller has six parameters to be tuned simultaneously: the gain $K_{s 1}, K_{s 2}$ and the time constants $T_{1}-T_{4}$. It worth mentioning that the controller parameters are selected after running the C-JAYA algorithm several times. A disturbance with $60 \mathrm{~ms}$ fault time is applied at the level of the optimization process, and a time-domain stability performance index is minimized. Also, four loading conditions are simultaneously considered. The optimal controller parameters are selected for the minimum value of the performance index.

\subsection{Design Method}

The dual-input power system stabilizer is used to ameliorate the stability of the power system when it faces a disturbance by reducing the rotor oscillations. To look for the optimal values of PSS parameters, the rotor speed deviation is utilized in the target function. Hence, an index performance obtained by the integral of time absolute error (ITAE) is adopted.

$$
J=\sum_{i=1}^{N P} \int_{0}^{t_{\min }} t\left|\Delta \omega_{i}\right| d t
$$


where $\Delta \omega_{i}$ is the rotor deviation and $t_{\min }$ is the simulation time. The problem design can be defined below, where all inequalities are the DIPSS parameters' bounds.

We minimize the $J$ subject to

$$
\begin{aligned}
K_{S 1}^{\min } & \leq K_{s 1} \leq K_{S 1}^{\max } \\
K_{S 2}^{\min } & \leq K_{s 2} \leq K_{S 2}^{\max } \\
T_{1}^{\min } & \leq T_{1} \leq T_{1}^{\max } \\
T_{2}^{\min } & \leq T_{2} \leq T_{2}^{\max } \\
T_{3}^{\min } & \leq T_{3} \leq T_{3}^{\max } \\
T_{4}{ }^{\min } & \leq T_{4} \leq T_{4}{ }^{\max }
\end{aligned}
$$

The controller gains a range between $[-100,-10]$ for $K_{s 1}$ and between $[10,100]$ for $K_{s 2}$. The range of the time constants is $[0.01,2]$.

\subsection{Appling of C-JAYA to Problem Stability}

To solve the aforementioned problem, C-JAYA is applied to look for the optimal parameters of the controller. In this context, we set the value of the generation number to 100. Table 1 shows the optimal controller parameters.

Table 1. Optimal obtained parameters.

\begin{tabular}{ccccccc}
\hline Method & $\boldsymbol{K}_{\boldsymbol{s} 1}$ & $\boldsymbol{K}_{\boldsymbol{s} 2}$ & $\boldsymbol{T}_{1}$ & $\boldsymbol{T}_{2}$ & $\boldsymbol{T}_{3}$ & $\boldsymbol{T}_{4}$ \\
\hline C-JAYA & -47.0458 & 95.0377 & 1.9750 & 0.1059 & 0.3624 & 1.8487 \\
JAYA & -12.1393 & 33.1568 & 1.8413 & 0.2951 & 1.4674 & 1.9591 \\
PSO & -18.3154 & 87.0993 & 1.8328 & 0.4180 & 1.9986 & 0.0111 \\
CS & -16.9978 & 74.6285 & 1.7516 & 0.1885 & 0.4841 & 1.7070 \\
\hline
\end{tabular}

Figure 7 shows the convergence curve of the ITAE target function J versus the number of generations. It was found that the C-JAYA algorithm provides faster convergence than the traditional JAYA, PSO and CS techniques.

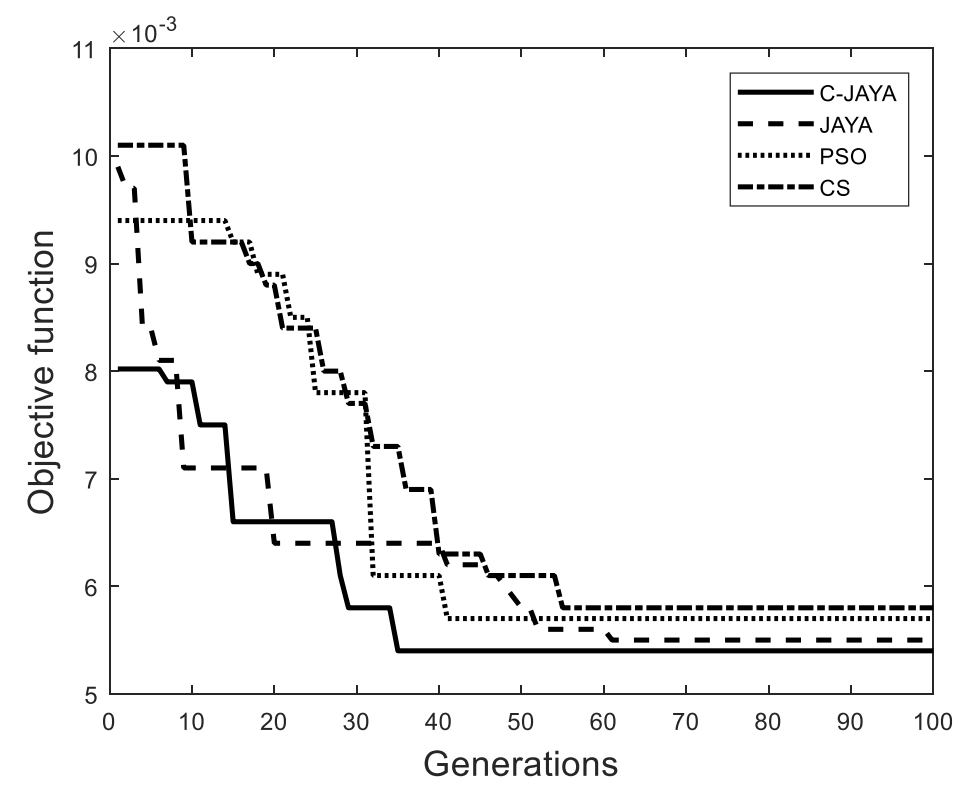

Figure 7. Objective function variation. 


\section{Simulations}

To assess the robustness and effectiveness of the proposed dual-input power system stabilizer, four different loading conditions are given in Table 2. The system data of the SMIB power system are provided in Appendix A. To assess the system's behavior under transient conditions, a three-phase fault was applied at the infinite bus at $t=1 \mathrm{~s}$.

Table 2. Loading conditions.

\begin{tabular}{ccc}
\hline Loading & $\mathbf{P}(\mathbf{p u})$ & $\mathbf{Q}(\mathbf{p u})$ \\
\hline Case 1 & 1 & 0.015 \\
Case 2 & 1 & -0.1 \\
Case 3 & 0.8 & 0.5 \\
Case 4 & 0.95 & 0.3 \\
\hline
\end{tabular}

The effectiveness of the suggested C-JAYAPSS controller is compared to JAYAPSS, PSOPSS and CSPSS. It is notable that all simulations are conducted using the nonlinear power system model.

Under severe conditions, the suggested C-JAYAPSS controller's behavior is verified by applying a three-phase fault with a six-cycle duration at the infinite bus, at the end of one transmission line, over a wide range of loading conditions. The fault clearness is performed without line tripping. The suggested PSS controller's effectiveness is demonstrated via a comparison to dual-input PSS designed using three well-known techniques: original JAYA, PSO and cuckoo search. The speed deviation of the generator with case1 loading conditions is shown in Figure 8. The system response indicates that the proposed C-JAYAPSS provides good damping characteristics and enhances the SMIB power system's dynamic stability. The controller tuned by the original JAYA achieves superior damping compared to the PSS and CS methods. Figure 9 shows the electrical output power response. The proposed stabilizers outperform all comparative techniques. The field voltage response depicted in Figure 10 indicates that the control effort is significantly reduced with the design approach. The C-JAYAPSS controller's ability to dampen electromechanical oscillations under case2, case 3 and case 4 loading conditions can be seen in Figures 11-13. Despite loading condition variations, the proposed controller provides a good damping performance and remains ranked first among all other comparative techniques.

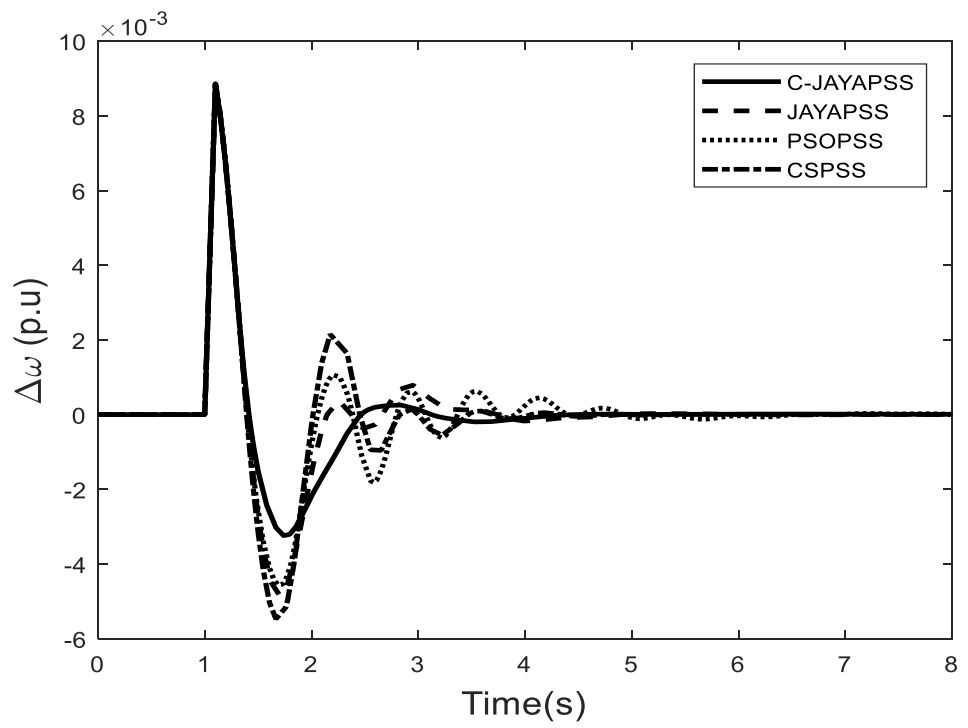

Figure 8. Rotor speed response for a six-cycle fault disturbance with case 1 . 


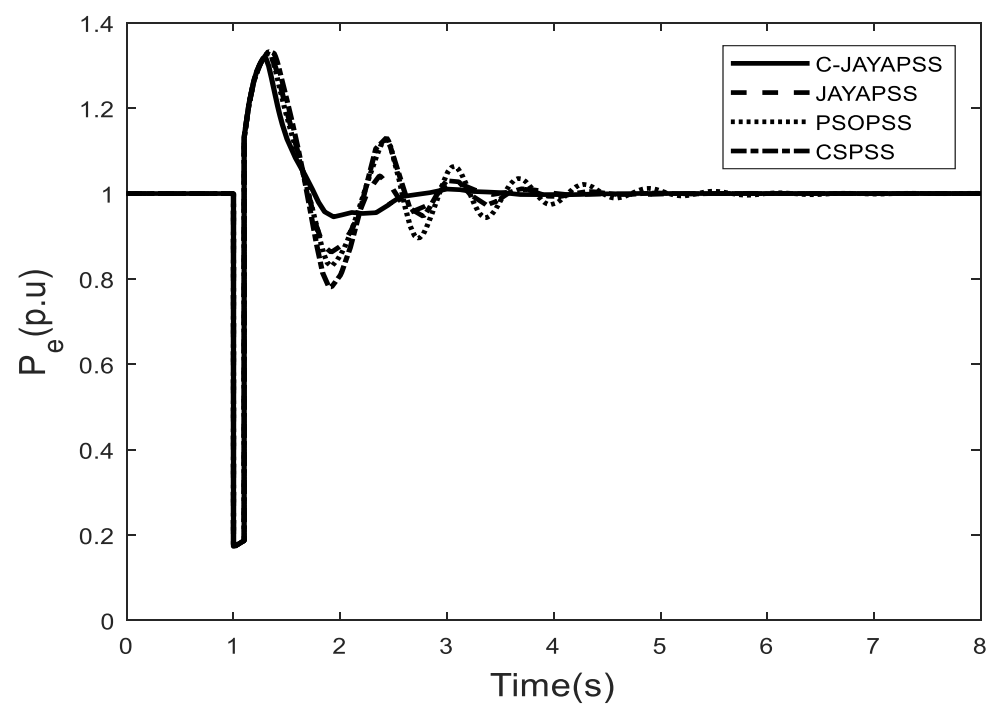

Figure 9. Electrical output power response for a six-cycle fault disturbance with case 1.

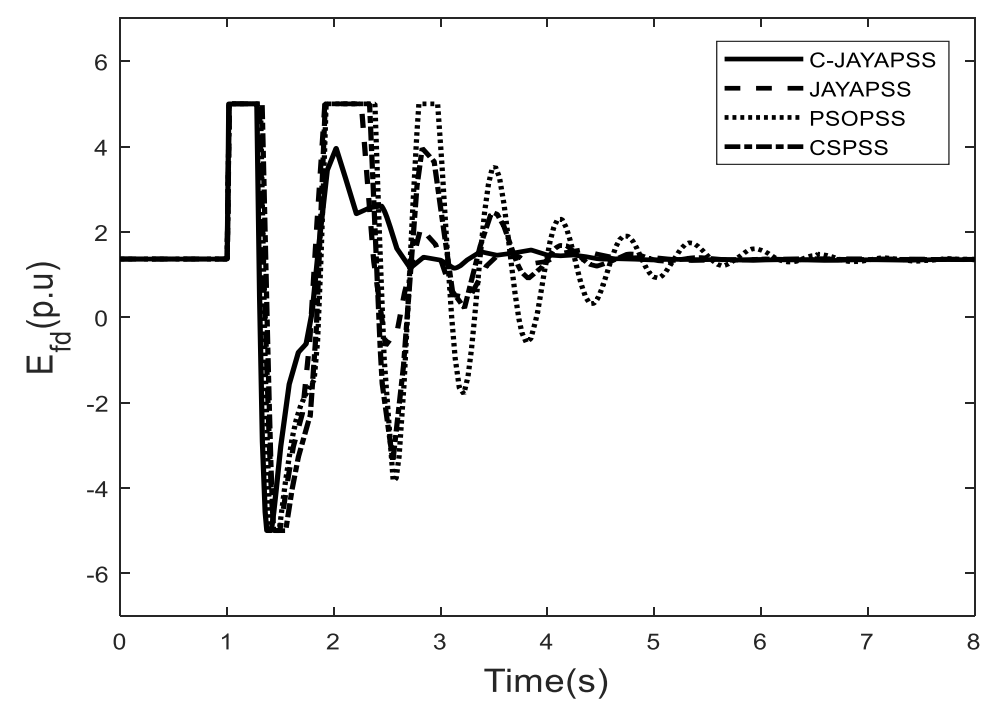

Figure 10. The field voltage for a six-cycle fault disturbance with case 1.

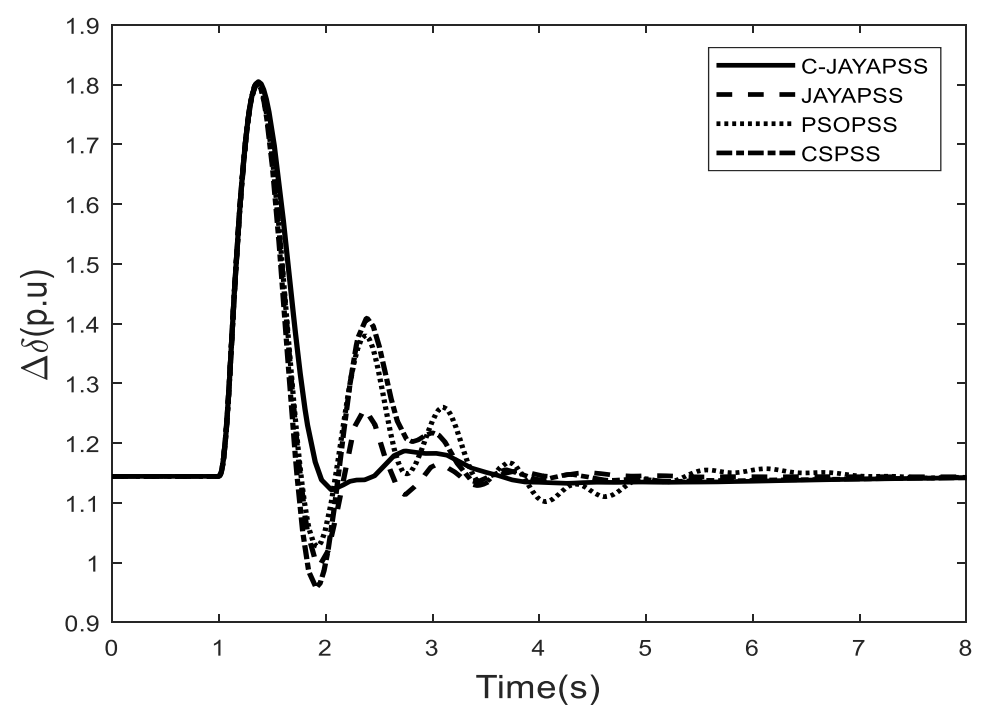

Figure 11. Rotor angle response for a six-cycle fault disturbance with case 2. 


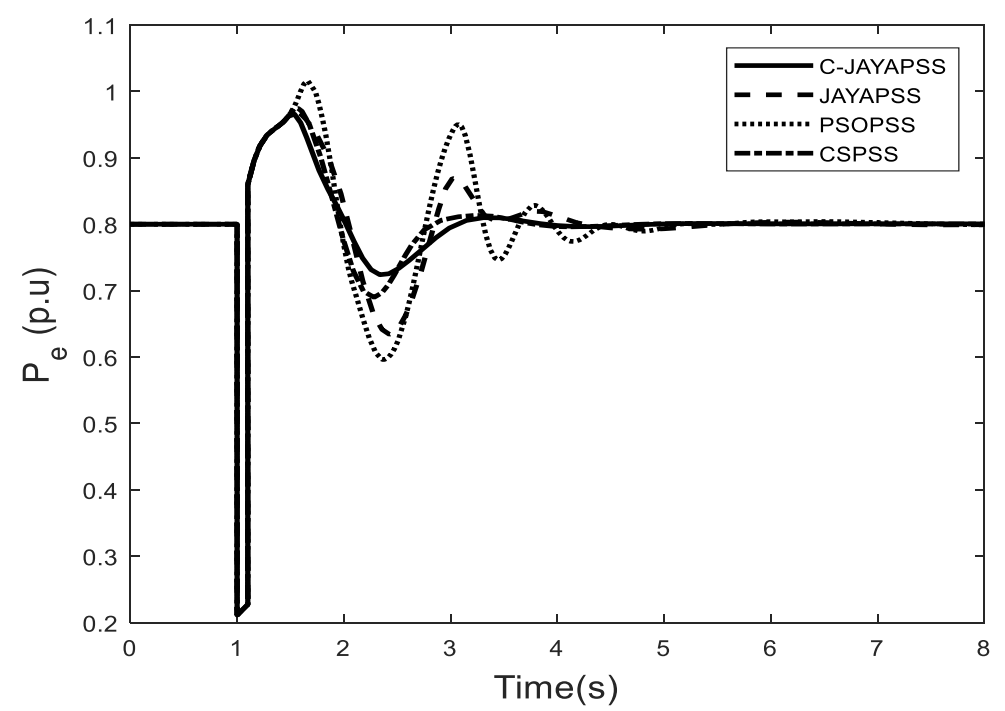

Figure 12. Electric power response for a six-cycle fault disturbance with case 3.

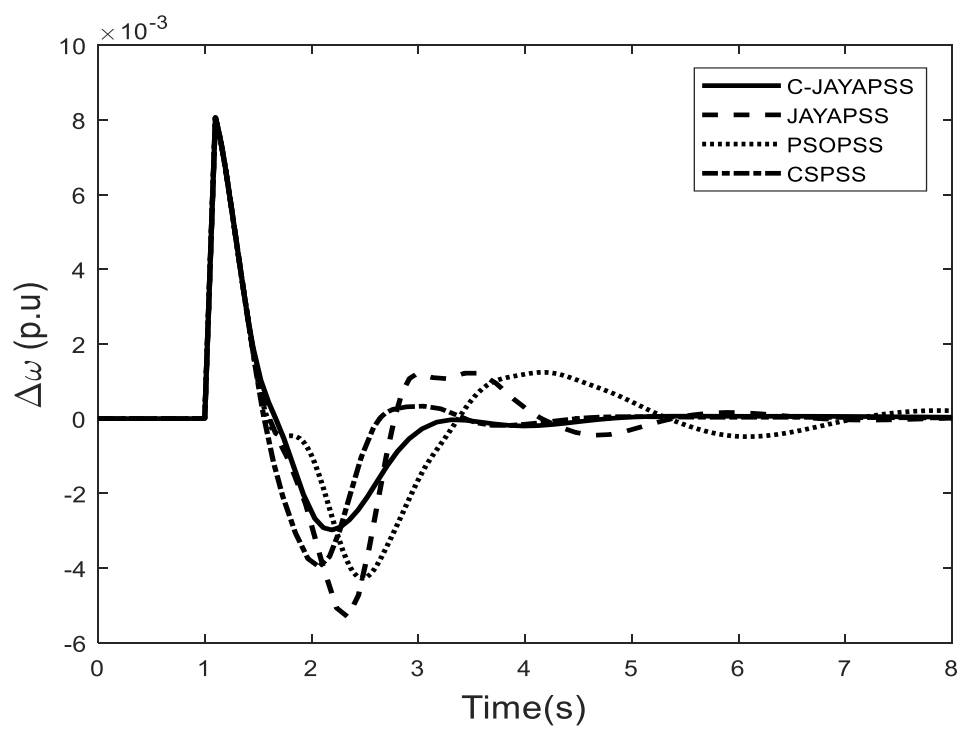

Figure 13. Rotor speed response for a six-cycle fault disturbance with case 4 .

To clearly demonstrate the superiority of the numerical performance of the proposed controller, two computational techniques are involved: the figure of demerit (FD) and the integral of the time multiplied by the absolute value of the error (ITAE) based on the system response are defined as:

$$
\begin{gathered}
I T A E=100 \int_{0}^{8} t\left(\left|\Delta \omega_{1}\right|+\left|\Delta \omega_{2}\right|+\left|\Delta \omega_{3}\right|\right) \\
F D=T_{s}^{2}+(50 U S)^{2}+(5 \text { OS })^{2}
\end{gathered}
$$

where $T_{S}$ is the settling time of the rotor angle deviation, $O S$ is the overshoot, and $U S$ is the undershoot.

The values of the performance indices for all loading conditions are given in Table 3. It can be seen that the proposed controller achieves the best performance since it provides smaller values for the ITAE and FD. 
Table 3. Performance indices' values.

\begin{tabular}{ccccccccc}
\hline Method & ITAE & \multicolumn{7}{c}{ FD } \\
\hline & Case 1 & Case 2 & Case 3 & Case 4 & Case 1 & Case 2 & Case 3 & Case 4 \\
C-JAYAPSS & 0.87 & 0.94 & 0.92 & 1.03 & 16.21 & 19.38 & 21.04 & 24.12 \\
JAYAPSS & 0.93 & 1.04 & 1.14 & 1.11 & 21.36 & 25.14 & 27.77 & 28.65 \\
PSOPSS & 1.01 & 1.13 & 1.38 & 1.45 & 28.74 & 32.88 & 39.15 & 52.09 \\
CPSS & 1.17 & 1.31 & 1.05 & 1.21 & 44.51 & 56.71 & 23.19 & 33.67 \\
\hline
\end{tabular}

\section{Conclusions}

In this paper, dual-input PSS was effectively tuned by using a new enhancement technique. A SMIB test system under various loading conditions was investigated to assess the suggested C-JAYAPSS controller. This novel method was conducted many times to look for the optimal results. The issue of PSS tuning parameters, which improve the damping at various loading conditions, was stated as an enhancement problem. A time-domain target function was introduced and solved by the C-JAYA algorithm. The proposed controller was compared with the JAYAPSS, PSOPSS and CSPSS methods. The nonlinear simulation was composed of the generator's rotor speed, electrical output power and field voltage. The obtained results showed the effective performance of C-JAYAPSS in reducing rotor oscillations for various loading conditions. In future work, the suggested method can be implemented to improve the stability of a multimachine test system and real-life power network over a wide range of operating conditions.

Author Contributions: Conceptualization, B.M.A. and A.F.; methodology, B.M.A.; software, A.F.; validation, A.F., K.A. and T.G.; formal analysis, B.M.A.; investigation, A.F.; resources, K.A.; data curation, T.G.; writing-original draft preparation, A.F.; writing-review and editing, A.F.; visualization, K.A.; supervision, B.M.A. All authors have read and agreed to the published version of the manuscript.

Funding: This research was funded by the Deanship of the Scientific Research of the University of Ha'il, Saudi Arabia (project: RG-191245).

Institutional Review Board Statement: Not applicable.

Informed Consent Statement: Not applicable.

Data Availability Statement: Not applicable.

Conflicts of Interest: The authors declare no conflict of interest.

\section{Appendix A}

System Data

Generator: $\mathrm{M}=9.26 ; \mathrm{D}=0 ; x_{d}=0.973$ p.u.

$x_{q}=0.55$ p.u; $x_{d}^{\prime}=0.19$ p.u; $T_{d 0}^{\prime}=7.76$ s.

$P_{e}=1$ p.u; $Q_{e}=0.015$ p.u; $\delta_{0}=67.61^{\circ}$.

Exciter: $K_{A}=50 ; T_{A}=0.05 \mathrm{~s}$.

Transmission line: $\mathrm{R}=-0.034$ p.u, $\mathrm{X}=0.997$ p.u.

$\mathrm{G}=0.234$ p.u, $\mathrm{B}=0.262$ p.u

\section{References}

1. Ghasemi, A.; Shayeghi, H.; Alkhatib, H. Robust design of multimachine power system stabilizers using fuzzy gravitational search algorithm. Int. J. Electr. Power Energy Syst. 2013, 51, 190-200. [CrossRef]

2. Pai, M.A.; Sen Gupta, D.P.; Padiyar, K.R. Small Signal Analysis of Power Systems, 1st ed.; Narosa Publishing House: New Dehli, India, 2004; p. 3.

3. Khodabakhshian, A.; Hemmati, R.; Moazzami, M. Multi-band power system stabilizer design by using CPCE algorithm for multi-machine power system. Electr. Power Syst. Res. 2013, 101, 36-48. [CrossRef]

4. Chatterjee, A.; Ghoshal, S.P.; Mukherjee, V. Chaotic ant swarm optimization for fuzzy-based tuning of power system stabilizer. Int. J. Electr. Power Energy Syst. 2011, 33, 657-672. [CrossRef] 
5. Ray, P.K.; Paital, S.R.; Mohanty, A.; Foo, Y.E.; Krishnan, A.; Gooi, H.B.; Amaratunga, G.A. A hybrid firefly-swarm optimized fractional order interval type-2 fuzzy PID-PSS for transient stability improvement. IEEE Trans. Ind. Appl. 2019, 55, 6486-6498. [CrossRef]

6. Chaib, L.; Choucha, A.; Arif, S. Optimal design and tuning of novel fractional order PID power system stabilizer using a new metaheuristic Bat algorithm. Ain Shams Eng. J. 2017, 8, 113-125. [CrossRef]

7. Zhang, Y.; Jin, Z.; Chen, Y. Hybrid teaching-learning-based optimization and neural network algorithm for engineering design optimization problems. Knowl.-Based Syst. 2020, 187, 104836. [CrossRef]

8. Sun, G.; Zhang, H.; Fang, J.; Li, G.; Li, Q. A new multi-objective discrete robust optimization algorithm for engineering design. Appl. Math. Model. 2018, 53, 602-621. [CrossRef]

9. Beirami, A.; Vahidinasab, V.; Shafie-khah, M.; Catalão, J.P. Multiobjective ray optimization algorithm as a solution strategy for solving non-convex problems: A power generation scheduling case study. Int. J. Electr. Power Energy Syst. 2020, $119,105967$. [CrossRef]

10. Farah, A.; Belazi, A. A novel chaotic Jaya algorithm for unconstrained numerical optimization. Nonlinear Dyn. 2018, 93, 1451-1480. [CrossRef]

11. Rao, R.V.; More, K.C. Optimal design and analysis of mechanical draft cooling tower using improved Jaya algorithm. Int. J. Refrig. 2017, 82, 312-324. [CrossRef]

12. Rao, R.V.; Saroj, A. An elitism-based self-adaptive multi-population Jaya algorithm and its applications. Soft Comput. 2019, 23, 4383-4406. [CrossRef]

13. Caldeira, R.H.; Gnanavelbabu, A. Solving the flexible job shop scheduling problem using an improved Jaya algorithm. Comput. Ind. Eng. 2019, 137, 106064. [CrossRef]

14. Raut, U.; Mishra, S. An improved Elitist-Jaya algorithm for simultaneous network reconfiguration and DG allocation in power distribution systems. Renew. Energy Focus 2019, 30, 92-106. [CrossRef]

15. Guesmi, T.; Farah, A.; Marouani, I.; Alshammari, B.; Abdallah, H.H. Chaotic sine-cosine algorithm for chance-constrained economic emission dispatch problem including wind energy. IET Renew. Power Gener. 2020, 14, 1808-1821. [CrossRef]

16. Yousri, D.; Allam, D.; Eteiba, M.B. Chaotic whale optimizer variants for parameters estimation of the chaotic behavior in Permanent Magnet Synchronous Motor. Appl. Soft Comput. 2019, 74, 479-503. [CrossRef]

17. García-Ródenas, R.; Linares, L.J.; López-Gómez, J.A. A memetic chaotic gravitational search algorithm for unconstrained global optimization problems. Appl. Soft Comput. 2019, 79, 14-29. [CrossRef]

18. Rizk-Allah, R.M.; Hassanien, A.E.; Bhattacharyya, S. Chaotic crow search algorithm for fractional optimization problems. Appl. Soft Comput. 2018, 71, 1161-1175. [CrossRef]

19. Kaur, G.; Arora, S. Chaotic whale optimization algorithm. J. Comput. Des. Eng. 2018, 5, 275-284. [CrossRef]

20. Sayed, G.I.; Khoriba, G.; Haggag, M.H. A novel chaotic salp swarm algorithm for global optimization and feature selection. Appl. Intell. 2018, 48, 3462-3481. [CrossRef]

21. Too, J.; Abdullah, A.R. Chaotic atom search optimization for feature selection. Arab. J. Sci. Eng. 2020, 45, 6063-6079. [CrossRef]

22. Tharwat, A.; Hassanien, A.E. Chaotic antlion algorithm for parameter optimization of support vector machine. Appl. Intell. 2018, 48, 670-686. [CrossRef]

23. Farah, A.; Guesmi, T.; Abdallah, H.H.; Ouali, A. A novel chaotic teaching-learning-based optimization algorithm for multimachine power system stabilizers design problem. Int. J. Electr. Power Energy Syst. 2016, 77, 197-209. [CrossRef]

24. Peres, W.; Júnior, I.C.S.; Passos Filho, J.A. Gradient based hybrid metaheuristics for robust tuning of power system stabilizers. Int. J. Electr. Power Energy Syst. 2018, 95, 47-72. [CrossRef]

25. Butti, D.; Mangipudi, S.K.; Rayapudi, S.R. An improved whale optimization algorithm for the design of multi-machine power system stabilizer. Int. Trans. Electr. Energy Syst. 2020, 30, e12314. [CrossRef]

26. Abd Elazim, S.M.; Ali, E.S. Optimal power system stabilizers design via cuckoo search algorithm. Int. J. Electr. Power Energy Syst. 2016, 75, 99-107. [CrossRef]

27. Rao, R.V. Jaya: An Advanced Optimization Algorithm and Its Engineering Applications; Springer: Berlin/Heidelberg, Germany, 2019; pp. 770-780.

28. Li, C.; Zhou, X.; Gao, D.Y. Stable trajectory of logistic map. Nonlinear Dyn. 2014, 78, 209-217. [CrossRef] 